\title{
Recent progress in microfiltration polypropylene membrane fabrication by stretching method
}

\author{
Anak Agung Istri Agung Sri Komaladewi ${ }^{1}$, Putu Teta Prihartini Aryanti ${ }^{2}$, Graecia Lugito ${ }^{3}$, I Wayan Surata $^{1}$, and I Gede \\ Wenten ${ }^{3, *}$ \\ ${ }^{1}$ Mechanical Eng. Dept., Udayana University, Jl. Raya Kampus UNUD, Bukit Jimbaran, Kuta Selatan, Badung, Bali-803611 \\ ${ }^{2}$ Chemical Eng. Dept., Universitas Jenderal Achmad Yani, Jl. Ters. Jend. Sudirman PO BOX 148, Cimahi \\ ${ }^{3}$ Chemical Eng. Dept., Institut Teknologi Bandung, Jl. Ganesha 10, Bandung-40132
}

\begin{abstract}
Microfiltration polypropylene (MF-PP) membrane has been widely used in many industries due to their excellent combination of good separation performances and low production cost. In addition to membrane configuration, the structure of MF-PP membrane also plays an important role in separation performance. MF-PP membrane is commonly produced by thermal induced phase separation (TIPS) and stretching. TIPS is the simplest one where the polymer is dissolved in a solvent at a decent temperature and then cooled to induce phase separation which leads to the formation of microporous structure. However, this method is limited by the nature of PP that is difficult to dissolve in organic solvents and the solventcontaminated effluent produced during the fabrication process. Therefore, the stretching method is more favorably used. The Stretching method involves four processing stages in sequence (i.e. melt-extrusion, annealing, stretching, and heat setting). Polymer composition, extrusion draw ratio, as well as stretching rate and temperature, are important parameters that significantly affect the pore structures evolved and thus the properties as well as the performances of MF-PP membrane. In this paper, the recent development of MFPP fabrication by stretching methods as well as the parameters involved in each method will be reviewed and discussed comprehensively.
\end{abstract}

\section{Introduction}

Polypropylene (PP) has been utilized for polymer-basedmembrane productions due to its outstanding properties resulting in a perfect balance between cost and performances. $\mathrm{PP}$ is a non-toxic material with high thermal, mechanical, and chemical resistance. This semicrystalline polymer is easy to process as well. Publications on PP membranes began in the 1980s, focussing on its tremendous applications (Figure 1). For over than three decades, the study on PP-membranes for water treatment [1-3], gas separation [4-6], energy storage [7-10], as well as medical applications [11, 12] keep increasing for continuous improvements of their performances (permeability, selectivity, durability, etc.).

The separation performances of a polymer membrane are determined by its intrinsic properties such as polymer crystallinity, hydrophobicity/hydrophilicity, generated charge, surface roughness, as well as porous structure across the membrane [13-16]. According to their average pore diameter, membranes can be classified into four classes: (1) conventional filtration $(10-100 \mu \mathrm{m})$, microfiltration $(0.1-10 \mu \mathrm{m})$, ultrafiltration $(1-100 \mathrm{~nm})$ and reverse osmosis $(\sim 0.1 \mathrm{~nm}) \quad[17,18]$. Most commercialized PP membranes are classified as microfiltration (MF) membrane. The MF-PP membranes are commonly fabricated by TIPS (which is also known as solution casting method or wet method) and stretching (or dry method) [19-21].

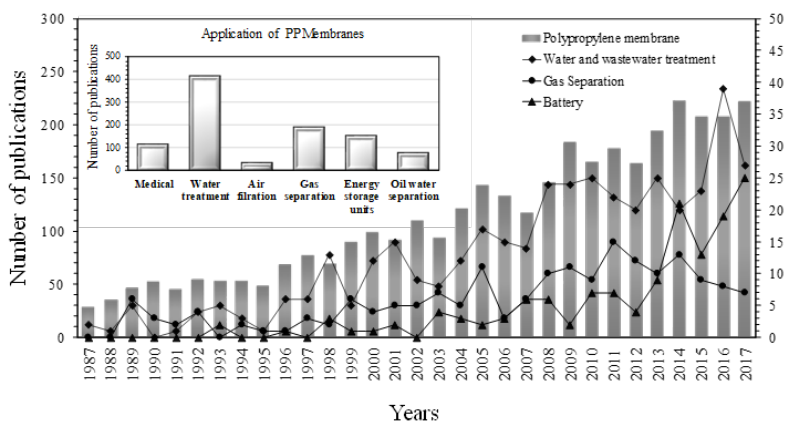

Fig. 1. Number of Scopus indexed papers on "Polypropylene Membranes" in the last 20 years (query: TITLE-ABS-KEY "polypropylene membrane", "water treatment" AND "wastewater treatment", "medical", "air filtration", "gas separation", "battery", and "oil-water separation").

The MF-PP membrane developed from the TIPS method was introduced by Castro in 1970s [22]. PP resins are dissolved in an organic solvent above its melting temperature to produce a homogenous PP solution, then driven to phase separation by quenching the solution. Subsequent to the solvent extraction from the solution, the porous structure is formed [23]. Upon quenching, crystal nuclei are formed immediately within

\footnotetext{
* Corresponding author: igw@che.itb.ac.id
} 
the polymer solution and continuously grow for a period of time to produce MF-PP membrane of various structures [24]. After the membrane structure is entirely formed, the remaining solvent could be removed through evaporation [25], leaching [26], or freeze-drying method [27]. Despite a simple and controllable procedure, the preparation of PP membranes using TIPS method is limited by the difficulty of dissolving PP; due to its high crystallinity, PP does not dissolve in most of the commercial organic solvents. Therefore, the simple dry stretching method becomes more favorable.

Reports on MF-PP membrane fabrication by stretching method as well as study on various factors affecting the morphology and permeation of the fabricated MF-PP membranes are abundant and keep increasing in number. However, the comprehensive review of those reports is very limited. This article is intended to review the recent progress of MF-PP membrane fabrication by stretching method as well as insights on how to "tailor" the pores' structure of the membranes to increase their performances

\section{Preparation of MF-PP Membrane by Stretching Method}

Almost all commercial PP membranes are fabricated from the semicrystalline isotactic-polypropylene (i-PP) [28]. The i-PP has a linear chemical structure of $\left[-\mathrm{CH}_{2} \mathrm{CH}\left(\mathrm{CH}_{3}\right)-\right]_{\mathrm{n}}$, where all the methyl groups $\left(-\mathrm{CH}_{3}\right)$ lie on a single side of the carbon backbone (Fig. 2A). Such configuration allows the i-PP chains to arrange in the form of highly oriented shish-kebab lamellae (Fig. 2B) or spherulite (Fig. 2C) and achieve a high degree of crystallinity. With a compact crystalline structure, consequently, the i-PP has an excellent resistance to stress, cracking, and chemical reaction.

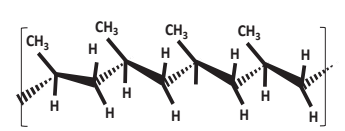

(a)

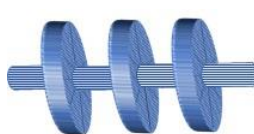

(b)

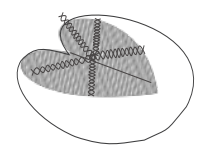

(c)
Fig. 1. Chemical structure of isotactic-polypropylene (i-PP) (A) as well as illustrations of shish-kebab (B) and spherulitic arrangements (C) of the polymer [29]

The fabrication of microporous structures within the polymer membrane by stretching methods was firstly introduced by Celanese Corporation in 1974 [30]. There are four consecutive stages in stretching method that have to be carried out to obtain a satisfactory porous membrane. First is creating a precursor film that contains the desired lamellar morphology (i.e., an oriented shishkebab structure); this can be achieved through meltextrusion. Second is annealing the precursor film at high temperatures to improve the crystalline structure. Third is cold-stretching, usually at room temperature to create pores by lamellae separation before hot-stretching at elevated temperature to enlarge the pores. The final stage is heat-setting the membrane to maintain dimensional stability and avoid shrinkage [31]. Fig. 3 displays the schematic process diagram of MF-PP membrane fabrication via stretching method.

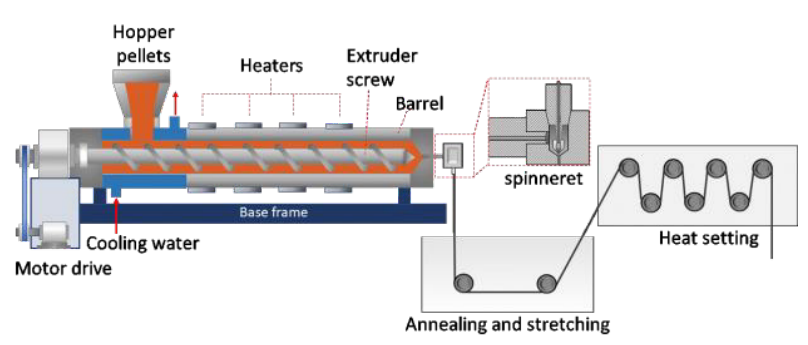

Fig. 2. Schematic process diagram for MF-PP membrane fabrication via stretching method

\subsection{Melt-extrusion}

Melt-extrusion of the polymer pellets is conducted in an extruder equipped with a feeding hopper, barrels, single or twin screw driving unit, a dying system, and other monitoring tools (such as temperature controller, screw speed controller, pressure gauge, etc). Most of the commercial extruders have a modular design that allows the interchangeable sections and process modification to meet particular requirements [32].

The melt-extrusion process happens in four zones: (1) feed zone, (2) transition and metering zone, (3) die zone, and (4) downstream processing zone [33]. The solid polymers are first transported by a screw to the transition zone, where the polymers are mixed and melted. The molten polymers are moved to the metering zone where molten polymer becomes homogeneous and uniformly delivered through the die [34]. During the melt-extrusion process, the molten PP goes through stress-induced crystallization state (in the die), which promotes the formation of a crystal layer (lamellar) instead of the spherulite [35]. Exit from the die, the temperature is set high to induce the relaxation of polymer chains and to improve the orientation of crystal blocks. The schematic change in polymer structure during the melt-extrusion stage is shown in Fig. 4.

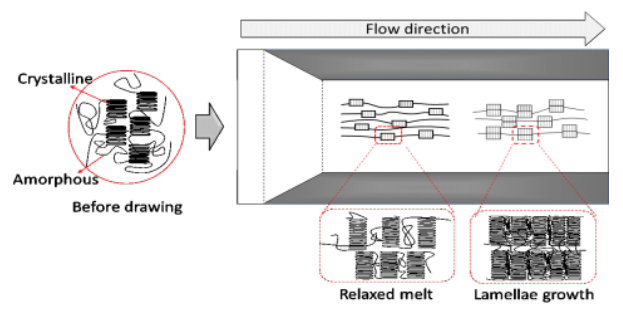

Fig. 3. Schematic of the orientation of polymer chain during melt-extrusion

The change in crystalline orientation could result after cooling process. By applying air cooling after the exit die, the PP precursor temperature decreases followed with the increase of applied stress in the polymer chains. Some amorphous chains are reorganized into higher chains orientation [36]. The morphology of lamellar as well as the crystallinity of PP precursor is not only depending on the extrusion conditions (such as temperature, molecular weight of polymer, draw ratio or 
roll speed to die exit velocity, and the presence of nucleating agent), but also the initial properties of the resins.

\subsection{Annealing and Stretching}

After the homogeneous molten PP was molded through a membrane molding, the molded PP membrane is annealed above its glass transition temperature $\left(T_{g}\right)$ or near its melting temperature $\left(T_{m}\right)$ [37]. The polymer chains in amorphous region would rearrange themselves into a more chain folded configuration (Fig. 5). Thus, the defects in polymer structure can be minimized or even eliminated [38]. Normally, the annealing process takes place in a short time. The influencing parameters that should be considered in the annealing process are temperature, time, and tension of annealing [39].

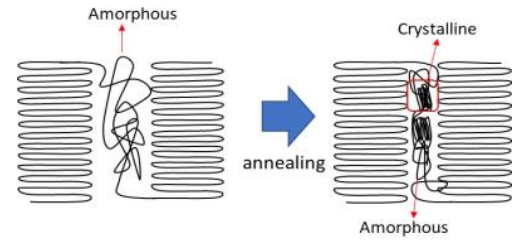

Fig. 4. Rearrangement of polymer chains in amorphous region during the annealing process

Stretching method is conducted to form microporous structures in the molded PP membrane by a temperature controlled uniaxial deformation (Fig. 6). Most of MF-PP membranes are commonly stretched by a two-stage process. First, the pores are nucleated by cold stretching to deform the crystal structure and then continued by hot stretching to enlarge the nucleated pore [40]. The cold stretching ratios were generally set at $30-40 \%$ [41], while the hot stretching was set at $100-200 \%$ [42]. Higher stretching ratio would induce more lamellae structure deformation. During the cold stretching, the mobility of polymer chains is retarded, and therefore, less deformation of crystalline structure was obtained.

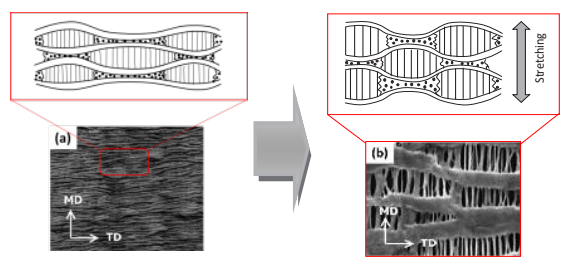

Fig. 5. Deformation of lamellar structure: (a) before and (b) after stretching [43]

In hot stretching, the temperature is set between the $T_{g}$ and $T_{m}$ of PP to induce chain extension and orientation polymer chain followed by crystallization by elongation flow. The rate of elongation flow can be adjusted to promote a high-oriented (shish and kebab) crystals form spherulitic crystal form [44]. The highlyoriented crystal structure resulted when the stretching flow is high enough. The hot-stretching (at high temperature and elongation flow) assists the disentanglement of polymer chain and promotes the formation of connecting bridge.

\subsection{Heat Setting}

During the heat-setting stage, some polymer chains at the connecting bridge are crystallized. The crystals that grow around the separated lamellar have a better dimensional stability. Therefore, the crystallinity of the stretched membrane increases, which lead to the increase of both tensile and modulus properties of the produced MF-PP membrane. Simultaneously, the rearrangement of polymer chains at a higher temperature leads to the reduction of membrane permeability [45]. Therefore, the selection of temperature and time in the heat-setting stage are crucial. Most of the heat-setting processes are conducted at $130-145^{\circ} \mathrm{C}$ for 10 minutes or more [37].

\section{Parameters Involved in Stretching Method}

A number of influencing parameters in stretching method in which the final structure of MF-PP membrane might be governed have been intensively studied. The most important operating parameters before stretching are the degree of orientation and crystallinity of polymer chains. Chain orientation induced by flow during the melt-extrusion process improves the kinetics of crystallization.

\subsection{Configuration and Molecular Weight of PP Resins}

Both configuration and molecular weight of PP [numberaverage molecular weight $\left(M_{n}\right)$, weight-average molecular weight $\left(M_{w}\right)$ distributions, as well as the polydispersity index (PDI)], affect the orientation of polymer chains, row-nucleated lamellar morphology, and crystallization kinetics during the melt-extrusion process [46]. High- $M_{w}$ polymers generate some proper row-nucleated lamellae since they have long thread-like polymer chain. Besides the characteristic of precursor (melt) polymer, $M_{w}$ of the polymer also affects the residence time (or relaxation time) and the operating temperature of the melting process. Higher $M_{w}$ and PDI required longer relaxation time [47].

Somani et al. [48] studied the effect of shear rate on the orientation of PP crystal chains. They found at a certain shear rate, only molecules with chain length (molecular weight) above the critical value $\left(M_{c}\right)$ could form stable oriented row-like nuclei (shish), while the shorter chains created lamellae over these nuclei sites. On the other research, Somani et al. [49] compared two types of i-PPs with identical number-average molecular weight $\left(M_{n}\right)$ but different weight-average $\left(M_{w}\right)$ and Zaverage $\left(M_{z}\right)$ molecular weights. The i-PP with higher $M_{w}$ showed a higher degree of crystal orientation and faster crystallization kinetics. The long chains preserved the flow-induced orientation longer than the short chains, and therefore dominant in forming shish lamellae.

\subsection{Operating Temperature and Draw Ratio in Melt-Extrusion Process}


Temperature and draw ratio (ratio of roll speed to die exit velocity) in melt-extrusion process play important roles in the resulted precursor structure, which related to the mechanism of shear-stress-induced crystallization and row-nucleated lamellar morphology [50]. Higher draw ratio (DR) generates longer chain extension and more row-nucleated sites for crystal lamellae to grow [51]. At the low DR, the lamellar are not well-aligned in a perpendicular direction to the flow. As DR increases, the lamellae align themselves perpendicular to the draw direction. Castejon et al. [31] studied the effect of DR on modified PP membrane with $10 \%$ wt of $\mathrm{CaCO}_{3}$. The modified PP membrane showed an increase in the orientation of the crystalline phase with the increasing of DR, which produced a finer precursor film.

The operating temperature affects the relaxation time of the polymer chain and crystallization rate [52]. The increase of melting temperature increases the viscosity of the polymer precursor and reduce the applied stress, shorten the relaxation time. The cooling stage at the right side of the exit die (Fig. 1) induces the significant change in intrinsic temperature and relaxation time of the polymer chain. In this condition, the crystallizations are induced by flow at low temperature and form a highly oriented lamellar structure. The shish structures are generated by the low $M_{w}$ chains followed by the growth and packing of the crystal site [52]. Studies on the effect of operating condition during melt extrusion on the morphology of the membrane are listed in Table 1.

Table 1. The effect of operating conditions in the meltextrusion process

\begin{tabular}{|c|c|c|c|}
\hline $\begin{array}{l}\text { Type of PP } \\
\text { (Molecular } \\
\text { weight) }\end{array}$ & $\begin{array}{l}\text { Operating } \\
\text { condition in } \\
\text { the extrusion } \\
\text { process }\end{array}$ & Results & Ref. \\
\hline $\begin{array}{l}\text { Modified } \\
\text { PP with } \\
10 \% \\
\mathrm{CaCO}_{3}\end{array}$ & $\begin{array}{l}\mathrm{DR}=60 \\
100 \\
\mathrm{DT}=210^{\circ} \mathrm{C}\end{array}$ & $\begin{array}{l}\text { The increase of DR } \\
\text { enhanced the } \\
\text { membrane porosity } \\
\text { and Gurley } \\
\text { permeability due to } \\
\text { the contribution of } \\
\text { debonding mechanism } \\
\text { of filler. }\end{array}$ & [31] \\
\hline $\begin{array}{l}\mathrm{i}-\mathrm{PP} \\
M_{w}= \\
376.000 \\
\mathrm{~g} / \mathrm{mol} \\
M_{n}= \\
55.600 \\
\mathrm{~g} \backslash \mathrm{mol}\end{array}$ & $\begin{array}{l}\mathrm{CT}=140 \text { and } \\
160^{\circ} \mathrm{C}\end{array}$ & $\begin{array}{l}\text { When the CT was } \\
\text { increased from } 140 \text { to } \\
160 \text {, the relaxation } \\
\text { time was reduced } \\
\text { from } 88 \text { to } 50 \text { second. } \\
\text { Higher temperature } \\
\text { (close to Tm) resulted } \\
\text { in a lower } \\
\text { crystallization rate. }\end{array}$ & [35] \\
\hline $\begin{array}{l}\beta \text {-i-PP } \\
M_{w}=3.8 \mathrm{x} \\
10^{5} \mathrm{~g} / \mathrm{mol} \\
M_{w} / M_{n}= \\
4.7)\end{array}$ & $\begin{array}{l}\text { NA }=5 \% w t \\
\text { of NAB- } 83 \\
\text { DT }=220{ }^{\circ} \mathrm{C} \\
\text { CT }=110- \\
135^{\circ} \mathrm{C}\end{array}$ & $\begin{array}{lr}\text { The uniform } & \text { size } \\
\text { distribution } & \text { was } \\
\text { resulted after } \\
\text { stretching process } \\
\text { when the CT was } 126 \\
{ }^{\circ} \mathrm{C} \text {. }\end{array}$ & [53] \\
\hline \multicolumn{4}{|c|}{$\begin{array}{l}\text { Note: } \mathrm{CT}=\text { cooling temperature, } \mathrm{DT}=\text { die temperature, } \mathrm{MT}= \\
\text { Melting temperature, } \mathrm{NA}=\text { nucleating agent, } \mathrm{Tm}=\text { melt } \\
\text { temperature of polymer }\end{array}$} \\
\hline
\end{tabular}

Table 2. The effects of annealing process operating condition on the resulted PP membrane

\begin{tabular}{|c|c|c|c|c|c|}
\hline \multirow{2}{*}{$\begin{array}{c}\text { Type of } \\
\text { PP } \\
\text { (Molecul } \\
\text { ar } \\
\text { weight) } \\
\end{array}$} & \multirow{2}{*}{$\begin{array}{c}\text { Extrusion } \\
\text { parameter } \\
\mathbf{s}\end{array}$} & \multicolumn{2}{|c|}{\begin{tabular}{|c|} 
Annealing \\
\end{tabular}} & \multirow[t]{2}{*}{ Results } & \multirow[t]{2}{*}{ Ref. } \\
\hline & & Time & $\begin{array}{l}\text { Temp } \\
\left({ }^{\circ} \mathrm{C}\right)\end{array}$ & & \\
\hline $\begin{array}{l}\text { Homo-PP } \\
\left(M_{w}=754\right. \\
\mathrm{kg} / \mathrm{mol})\end{array}$ & $\begin{array}{l}\mathrm{MT}=210 \\
{ }^{\circ} \mathrm{C} \\
\mathrm{DR}=125 \\
\mathrm{CT}=80^{\circ} \mathrm{C}\end{array}$ & $\begin{array}{l}30 \\
\min \end{array}$ & $\begin{array}{l}105 \\
- \\
150\end{array}$ & $\begin{array}{l}\text { The } \\
\text { connection } \\
\text { bridge was } \\
\text { uniform up to } \\
145^{\circ} \mathrm{C} \text {. } \\
\text { Above } 145^{\circ} \mathrm{C} \\
\text { the lamellae } \\
\text { were non- } \\
\text { uniform. }\end{array}$ & [40] \\
\hline $\begin{array}{l}\text { i-PP } \\
M_{w}=307.0 \\
00 ; \\
M_{n}=15.60 \\
0\end{array}$ & $\begin{array}{l}\mathrm{DT}=200 \\
{ }^{\mathrm{C}} \mathrm{C} . \\
\mathrm{CT}=-70 \\
\text { (dry-ice } \\
\text { acetone } \\
\text { bath }\end{array}$ & $24 \mathrm{~h}$ & $\begin{array}{l}130 \\
- \\
155\end{array}$ & $\begin{array}{l}\text { Temperature } \\
\text { higher than } \\
150^{\circ} \mathrm{C} \\
\text { increased } \\
\text { crystal } \\
\text { dimension and } \\
\text { perfection. }\end{array}$ & [56] \\
\hline $\begin{array}{l}\text { i-PP } \\
\text { density: } \\
0.898 \\
\mathrm{~g} / \mathrm{cm}^{3}\end{array}$ & $\begin{array}{l}\mathrm{DT}=220 \\
{ }^{\circ} \mathrm{C} \\
\mathrm{DR}=35\end{array}$ & $\begin{array}{c}1-30 \\
\min \end{array}$ & $\begin{array}{l}120 \\
- \\
155\end{array}$ & $\begin{array}{l}\mathrm{T}_{\text {ann }} \text { of } 140^{\circ} \mathrm{C} \\
\text { was } \\
\text { recommended } \\
\text { The } 10 \mathrm{~min} \\
\text { annealing } \\
\text { time was } \\
\text { practically } \\
\text { enough for the } \\
\text { completion of } \\
\text { secondary } \\
\text { crystallization }\end{array}$ & [36] \\
\hline $\begin{array}{l}\text { i-PP } \\
M_{w}= \\
380.000, \\
M_{w} / M_{n}= \\
4-5\end{array}$ & $\begin{array}{l}\mathrm{MT}=182 \\
{ }^{\circ} \mathrm{C}\end{array}$ & - & $\begin{array}{l}160 \\
- \\
171\end{array}$ & $\begin{array}{l}\text { When } \mathrm{T}_{\mathrm{ann}}< \\
\mathrm{T}_{\mathrm{m}} \text {, the } \\
\text { change in } \\
\text { membrane } \\
\text { thickness did } \\
\text { not exceed } \\
30 \% \text {. }\end{array}$ & [57] \\
\hline $\begin{array}{l}\text { Linear PP } \\
\text { (T30S } \\
\text { PP) } M_{w}= \\
68.000\end{array}$ & $\begin{array}{l}\mathrm{DT}=200- \\
230^{\circ} \mathrm{C}\end{array}$ & $1 \mathrm{~h}$ & 140 & $\begin{array}{l}\text { When stress } \\
\text { acted during } \\
\text { the annealing } \\
\text { process, shish- } \\
\text { kebab crystal } \\
\text { structure and } \\
\text { rigid } \\
\text { amorphous } \\
\text { fraction were } \\
\text { formed. The } \\
\text { stress } \\
\text { impacted the } \\
\text { crystal } \\
\text { structure and } \\
\text { developed } \\
\text { different } \\
\text { structure } \\
\text { during } \\
\text { annealing }\end{array}$ & [58] \\
\hline $\begin{array}{l}\text { Note: } \mathrm{CT}= \\
\text { temperatur } \\
\text { Tann }=\mathrm{An}\end{array}$ & $\begin{array}{l}=\text { cooling tem } \\
\mathrm{e}, \mathrm{MF}=\text { mel } \\
\text { nealing temp }\end{array}$ & $\begin{array}{l}\text { gerat } \\
\text { flow }\end{array}$ & $\begin{array}{l}\mathrm{DR} \\
\mathrm{e}, \mathrm{M}\end{array}$ & $\begin{array}{l}\text { Iraw ratio, } \mathrm{DT}= \\
=\text { melting temper }\end{array}$ & \\
\hline
\end{tabular}




\subsection{Temperature and Time of Annealing}

The determination of annealing temperature depends on the initial properties of the PP $\left(M_{w}, T_{m}, T_{g}\right.$, etc. $)$ as well as the precursor PP produced during the melt-extrusion process. Most of the study reported that the increase of annealing temperature improved the connecting bridge and promoted pore distribution within the PP membrane until a certain temperature. Further increase of the annealing temperature would result in swelling which led to crystal imperfections due to the deterioration of crystal chains. During the annealing process, crystallization may occur at the amorphous regions along with secondary crystallization. The perfect lamellar structure during annealing stage would result in a stable connecting bridge [54]. The effects of annealing temperature and time on PP crystallization behavior are listed in Table 2.

\subsection{Stretching Temperature and Ratio}

The effect of stretching temperature and ratio to the resulted MF-PP membrane characteristics have been studied for a while now. Started with Nago et al. [55] who study the effect of stretching direction and ratio on MF-PP containing $\mathrm{CaCO}_{3}$ filler. Two stretching directions were applied, i.e. machine direction (MD) and transverse direction (TD). They found that stretching in MD was more effective for initiating the pore; while, the increase of stretching ratio resulted in finer PP structure. Tabatabaei et al. [50] reported that $30 \%$ is the optimum cold-stretching ratio, further increase reduced the membrane permeability. The cold-stretching temperature was found to reach its optimum permeability at $25^{\circ} \mathrm{C}$. Caihong et al. [42] found that the best pore structure and stable connecting bridge of PP precursor were achieved when the hot-stretching ratio set at $200 \%$ with annealing and stretching temperature of 145 and $130^{\circ} \mathrm{C}$, respectively. Further increase of hot-stretching ratio above $200 \%$ and stretching temperature above $130^{\circ} \mathrm{C}$ destructed some crystal chains at the connection bridge, resulting in inevitable shrinking of pore diameter and pore closure.

Besides of temperature and stretching ratio, the deformation of crystalline morphology also depends on draw ratio (DR), which is defined as the ratio between the rates of stretching and melt. DR value gives influence on the elongations of the stretched PP membrane and the crystal morphology as well. Higher DR was found enhancing the orientation of the polymer chain and deforming the spherulite structure as well as developing a fiber-like structure [44]. With further increase of DR, a part of deformed spherulites starts to form shish structures.

\subsection{Heat-Setting Time and Temperature}

Up to this time, only a few literature studies on the effect of heat setting on MF-PP membrane structure and performance. Caihong et al. [45] studied the effects of heat-setting temperature (from 135 to $155^{\circ} \mathrm{C}$ ) and found that higher temperature impeded the shrinkage of the MF membrane. However, too high heat-setting temperature might destroy the porous structure and reduce the permeability of the membrane. The MF membrane heatset at $145^{\circ} \mathrm{C}$ for $10 \mathrm{~min}$ shown the optimum permeability and dimensional stability with porosity of $46.8 \%$ and shrinkage percentage as low as $0.2 \%$. Further increase of heat-setting temperature to 150 and $155^{\circ} \mathrm{C}$ increased the Gurley value yet reduced the porosity of the membrane, hence, lower the permeability of the permeate through the PP membrane.

\section{Challenges and Closing Remarks}

Despite the fact that MF-PP membranes prepared by stretching method have been commercialized, and comprehensive knowledge on how to 'tailor' the pore structure of the membrane exists through selection of proper fabrication processing parameters, there is still a big challenge to further improve the performance of polymer membrane (e.g., flux, selectivity, mechanical strength, chemical resistance, and anti-fouling properties). In stretching process, the physical properties of the polymeric material (e.g., crystallinity, melting point, tensile strength, molecular configuration, etc.), as well as the applied processing parameters, govern the final porous structure and properties of the produced membranes. A hydrophobic nature of PP makes PPbased membrane more susceptible to fouling. The utilization of calcium carbonate $\left(\mathrm{CaCO}_{3}\right)$ fillers to created pores through the debonding of $\mathrm{CaCO}_{3}$ from the polymeric matrix by biaxially stretching may enhance the rigidity and hydrophilicity of the MF-PP membrane surface [59]. Yet, the final crystalline microstructure of the membrane would also be affected by these fillers, increasing the number of dependent parameters that have to be taken into considerations.

To facilitate molecular transport across the membrane, a high mechanical strength is a must for the durability of the membrane. The mechanical strength of the semicrystalline PP is proportional to the length of the polymeric chain, and thus the molecular weight of the polymer. However, the higher $M_{w}$ polymer has a higher glass transition temperature $\left(T_{g}\right)$ which increase the energy (temperature process), material selection as well as the dimension of the extruder (residence time) required for the melt-extrusion process.

Tracking the melt dynamics as well as the distribution of nucleation precursors of the polymer chains within the melt-extruder is also a challenge. Although has been studied for decades, the fundamental nature of the transient events in flow-induced crystallization remains concealed. Probing the events are formidable and challenging due to the lack of sophisticated instrument. Furthermore, the time for these precursors to appear decreases with increasing temperature suggesting that under intense shear, the nucleation of oriented crystallites is governed by a critical anisotropic configuration of polymer chains in the melt which attributed to the molecular mass distribution of the PP resin [60]. 
Due to the multistage processes of extrusion, annealing, stretching, and heat-setting, the processing parameters on the previous process become additional variables that determine the selection of processing parameters of the next process. This fabrication method requires intensive investigations on how processing parameters of each stage affect the final structure as well as the performances of the final product. A comprehensive approach to study the correlations between applied processing parameters - structure properties - membrane performance has to be developed.

\section{References}

1. C. Charcosset, I. Limayem, and H. Fessi, J. Chem. Technol. Biotechnol. 79, 209-18 (2004)

2. C. Charcosset, J. Food Eng. 92, 241-9 (2009)

3. A. M. Kansara, S. G. Chaudhri, and P. S. Singh, RSC Adv. 6, 61129-36 (2016)

4. Z. Qi and E. L. Cussler, J. Memb. Sci. 23, 321-32 (1985)

K. K. Sirkar, Chem. Eng. Comm. 157, 145-84 (1997)

6. P. Bulejko, M. Dohnal, J. Pospíšil, and T. Svěrák, Sep. Purif. Technol. (2017)

7. H. G. Kim, R. Kim, S. Kim, C. Choi, B. Kim, H. Guim, and H.-T. Kim, J. Ind. Eng. Chem. 60, 4016 (2018)

8. M. Yin, J. Huang, J. Yu, G. Chen, S. Qu, X. Wang and C. Li, Electrochim. Acta 260, 489-97 (2018)

9. H. J. Peng, D. W. Wang, J. Q. Huang, X. B. Cheng, Z. Yuan, F. Wei, and Q. Zhang, Adv. Sci. 3, (2016)

10. M.D. Larson, C. J. Simonson, R. W. Besant, and P. W. Gibson, J. Memb. Sci. 302, 136-49 (2007)

11. J. Zhao, L. Song, Q. Shi, S. Luan, and J. Yin, ACS Appl. Mater. Interfaces 5, 5260-8 (2013)

12. K. L. Dorrington, J. P. Gardaz, B. J. Bellhouse, and M. K. Sykes, J. Biomed. Eng. 8, 36-42 (1986)

13. P.T.P. Aryanti, M. Sianipar, M. Zunita, and I. G. Wenten, Membr. Water Treat. 8, 463-81 (2017)

14. Khoiruddin, P. T. P. Aryanti, A. N. Hakim, and I. G. Wenten, AIP Conf. Proc. 1840, 090006 (2017)

15. D. Ariono, P. T. P. Aryanti, S. Subagjo, and I. G. Wenten, AIP Conf. Proc. 1788, 030048 (2017)

16. D. Ariono, P. T. P. Aryanti, A. N. Hakim, S. Subagjo, and I. G. Wenten, AIP Conf. Proc. 1840, 090006 (2017)

17. I.G. Wenten, K. Khoiruddin, P. T. P. Aryanti, and A. N. Hakim, J. Memb. Sci. Res. 2, $42-58$ (2016)

18. R.W. Baker: John Wiley \& Sons, Ltd, (2012)

19. N.F. Himma, S. Anisah, N. Prasetya, and I. G. Wenten, J. Polym. Eng. 36, 329-62 (2016)

20. N. F. Himma, A. K. Wardani, and I. G. Wenten, Polym. Plast. Technol. Eng. 56, 184-94 (2017)

21. N. Tang, Q. Jia, H. Zhang, J. Li, and S. Cao, Desalination 256, 27-36 (2010)

22. A. J. Castro, 4,247,498, (1981)

23. Y. Lin, G. Chen, J. Yang, and X. Wang, Desalination 236, 8-15 (2009)

24. P.M. Atkinson and D. R. Lloyd, J. Memb. Sci. 175 , 225-38 (2000)
25. C. Fang, S. Jeon, S. Rajabzadeh, L. Cheng, L. Fang, and H. Matsuyama, J. Mater. Chem. A 6, 535-47 (2018)

26. I.J. Roh, S. Ramaswamy, W. B. Krantz, and A. R. Greenberg, J. Memb. Sci. 362, 211-20 (2010)

27. S. Rajabzadeh, T. Maruyama, T. Sotani, and H. Matsuyama, Sep. Purif. Technol. 63, 415-23 (2008)

28. B. Luo, Z. Li, J. Zhang, and X. Wang, Desalination 233, 19-31 (2008)

29. Z. Bashir, J. Odell, and A. Keller, J. Mater. Sci. 21, 3993-4002 (1986)

30. J.-J. Kim, T.-S. Jang, Y.-D. Kwon, U. Y. Kim and S. S. Kim, J. Membr. Sci. 93, 209-15 (1994)

31. P. Castejón, K. Habibi, A. Saffar, A. Ajji, A. B. Martínez and D. Arencón, Polymers 10, 33 (2017)

32. J. Breitenbach, Eur. J. Pharm. Biopharm. 54, 10717 (2002)

33. S. Singhal, V. K. Lohar, and V. Arora, Webmedcentral Pharm. Sci. 2(1), WMC001459 (2011)

34. M. Maniruzzaman, J. S. Boateng, M. J. Snowden, and D. Douroumis, ISRN Pharmaceutics 2012, (2012)

35. S. Coppola, L. Balzano, E. Gioffredi, P. L. Maffettone, and N. Grizzuti, Polymer 45, 3249-56 (2004)

36. S. Wang, A. Saffar, A. Ajji, H. Wu, and S. Y. Guo, Chin. J. Polym. Sci. (English Edition) 33, 1028-37 (2015)

37. J. Liu, X. L. Lu and C. R. Wu, J. Appl. Polym. Sci. 129, 1417-25 (2013)

38. A. Saffar, A. Ajji, P. J. Carreau, and M. R. Kamal, Polymer 55, 3156-67 (2014)

39. M. B. Johnson and G. L. Wilkes, J. Appl. Polym. Sci. 84, 1762-80 (2002)

40. C. Qi, X. Ruijie, W. Shuqiu, C. Changbin, M. Haibin, L. Caihong, L. Liangbin, and Z. Li, Polym. Int. 64, 446-52 (2015)

41. F. Sadeghi, A. Ajji, and P. J. Carreau, J. Memb. Sci. 292, 62-71 (2007)

42. L. Caihong, W. Shuqiu, X. Ruijie, C. Qi, H. Bing, P. Xinlong and S. Wenqiang, Polym. Bull. 70, 1353-66 (2013)

43. S. S. Zhang, Journal of Power Sources 164, 35164 (2007)

44. Y. G. Zhou, L. S. Turng, and C. Y. Shen, J. Polym. Sci., Part B: Polym. Phys. 48, 1223-34 (2010)

45. L. Caihong, W. Shuqiu, C. Qi, X. Ruijie, H. Bing, and S. Wenqiang, Polym. Int. 63, 584-8 (2014)

46. A. Nogales, B. Hsiao, R. Somani, S. Srinivas, A. Tsou, F. Balta-Calleja and T. Ezquerra, Polymer 42, 5247-56 (2001)

47. M.B. Johnson Mand G. L. Wilkes, J. Appl. Polym. Sci. 81, 2944-63 (2001)

48. R.H. Somani, B. S. Hsiao, A. Nogales, S. Srinivas, A. H. Tsou, I. Sics, F. J. Balta-Calleja, and T. A. Ezquerra, Macromolecules 33, 9385-94 (2000)

49. R.H. Somani, L. Yang, and B. S. Hsiao, Polymer 47, 5657-68 (2006)

50. S.H. Tabatabaei, P. J. Carreau, and A. Ajji, $J$. Memb. Sci. 325, 772-82 (2008) 
51. F. Sadeghi, A. Ajji and P. J. Carreau, Polym. Eng. Sci. 47, 1170-8 (2007)

52. S. H. Tabatabaei, P. J. Carreau, and A. Ajji, Polymer 50, 4228-40 (2009)

53. T. Wu, M. Xiang, Y. Cao, J. Kang, and F. Yang, RSC Adv. 4, 36689-701 (2014)

54. L. Caihong and X. Ruijie, (Cham: Springer International Publishing), (2017)

55. S. Nagō and Y. Mizutani, J. App. Polym. Sci. 68, 1543-53 (1998)

56. R. Natale, R. Russo, and V. Vittoria, J. Materials Sci. 27, 4350-4 (1992)

57. D. V. Novikov, G. K. Elyashevich, V. K. Lavrentyev, I. S. Kuryndin, A. Anžlovar, and V. Bukošek, Phys. Solid State 56, 396-404 (2014)

58. H. Shao, F. Wei, B. Wu, K. Zhang, Y. Yao, S. Liang, and S. Qin, RSC Adv. 6, 4271-9 (2016)

59. P. Castejón, K. Habibi, A. Saffar, A. Ajji, A. B. Martínez, and D. Arencón, Polymers 10, 33 (2018)

60. G. Kumaraswamy, J. A. Kornfield, F. Yeh, and B. S. Hsiao, Macromolecules 35, $1762-9$ (2002) 